\title{
A clarification concerning the butner study
}

\section{Commentary}

The Butner Study ${ }^{1}$ has been used to support that child porn only offenders actually engage in child sex contact offenses at significantly higher rates than expected. They found that $85 \%$ of their child porn only offenders had one or several contact victims that they had not been caught for. Several authors criticized that study primarily on the grounds of poor research design and biased data. This is a clarification of my article in which I cited the Butner Study.

As a national police and U.S. Probation trainer and consultant, I provide information addressing sexual predators and violent offenders in general and have always based my professional opinion on that which is supported by the literature. In my article Child Pornography Users \& Child Contact Offenders: Applications for Law Enforcement, Prosecution and Forensic Mental Health ${ }^{2}$ I cited the Butner Study. ${ }^{1}$ I wanted to make clarification about the veracity of the Butner Study claims.

Based on several reviews in the literature, there are significant concerns about the veracity of the Butner study and therefore concerns about the implications of the study on child porn offenders' risk assessment. The article apparently written by the Citizens for Change- America ${ }^{3}$ lays out much of the criticism of the Butner study. In short, there appears to be concerns including, but not limited to the following:

a. That the child porn offenders in the Butner Study, who were incarcerated, may have felt pressured to admit to having contact (touch) victims in order to remain in good standing in the treatment program.

b. That the study authors: had a bias in favor of proving that child porn only offenders were in fact more dangerous than previously thought; had failed to follow scientific method; had failed to obtain proper approval for their study; among other concerns.

c. That the study relied on polygraph examinations, which drew criticism from some in the scientific community because, polygraph is not often deemed reliable or accurate.

Other studies have found that child porn only offenders have admitted to having contact victims that they have not yet been caught for. For example, Seto et al., ${ }^{4}$ found that approximately $50 \%$ of their child porn only offenders admitted to having contact victims. The Butner study found that $85 \%$ of their child porn only offenders admitted to having contact victims that they had not yet been caught for. Regardless of whether the Butner study is found to be too seriously flawed to take serious or not, theirs is not the only study finding that child porn only offenders have one or multiple contact victims. While in fairness, most studies found that between $2-50 \%$ may have contact victims, the Butner study is the only study I am aware that found the high percentage of $85 \%$.

Relying on self-report is a complicated and often troubled method of gathering information. Some offenders may exaggerate their offense history in order to gain attention or to appear to be benefitting from treatment (gaining conscious by their admissions). Some offenders may continue to deny additional victims or offenses to protect their

\author{
Volume 6 Issue 4 - 2018
}

\author{
Scott A Johnson \\ Licensed Psychologist, USA
}

Correspondence: Scott A Johnson, Forensic Consultation, Licensed Psychologist, Florida, USA, Tel (612) 2693628 , Email scott@forensicconsultation.org

Received: May 09, 2018 | Published: July 18, 2018

appearance of innocence or to lessen their assessed potential risk for reoffense. However, self-report is often used and often relied upon because of a lack of alternative methodologies. In reference to gathering self-report data from incarcerated sex offenders, the task becomes complicated to the degree to which the offenders feel pressured to respond in a certain way. The offender's responses need to be confidential and the treatment staff and researchers should not have access identifying which offender admitted having contact or additional victims and in fairness, it appears that the offenders in the Butner study may not have had that anonymity.

Polygraph may be used as an effective tool to assess treatment and supervision compliance and offers some degree of accuracy though not be any means perfect. Polygraph results are not allowed as evidence in most courts and that is reason enough to have some concerns over the overall accuracy of polygraph examinations. However, on the other hand, polygraph results appear to have resulted in sufficient accuracy to be a useful and important tool in the treatment of sexual offenders as well as for the supervision of sex offenders. Despite the mixed result, polygraph is a valuable tool to hold a sex offender accountable for their past, current, and future behavior. Polygraph appears to be a valuable tool in the sex offender treatment field as well as for supervision.

In summary, the results of the Butner Study need to be taken with caution because of the criticism raised by the scientific community. This does not mean that child porn offenders engage in a victimless crime. The children depicted in the child porn are by definition victims- they have no power to stop the pornographers and a limited understanding of what they are being forced or requested to do. In addition, use of child porn contributes to the acceptance of children as sexual beings or sexual partners. It would be difficult to encourage or allow a child porn offender or a contact child sexual abuser continued access to any erotica involving children or child porn. ${ }^{5}$ The results of the Butner Study must now be questioned and not taken at face value.

\section{Acknowledgements}

None.

\section{Conflict of interest}

The author declares no conflict of interest. 


\section{References}

1. Bourke ML, Hernandez AE. The 'Butner Study' redux: A report of the incidence of hands-on child victimization by child pornography offenders. Journal of Family Violence. 2009;24(3):183-191.

2. Johnson SA. Child pornography users \& child contact offenders: applications for law enforcement, prosecution and forensic mental health. International Journal of Emergency Mental Health and Human Resilience. 2015;17(4):666-669.
3. Citizens for change, America. The butner study: a report on the fraudulent execution of the adam walsh act by the federal Bureau of prisons (BOP). 2018:1-13.

4. Seto MC, Hanson RK, Babchishin KM. Contact sexual offending by men with online sexual offenses. Sex Abuse. 2011;23(1):124-145.

5. Johnson SA. Erotica and the sexual offender: the importance of restricting sex offenders from using or possessing erotica and pornography. Forensic Res Criminol Int J. 2018;6(2):00186. 